\title{
Kinetics and Mechanism of Nanoparticles-Catalyzed Piperidinolysis of Anionic Phenyl Salicylate
}

\author{
Norazizah Abd. Razak and M. Niyaz Khan \\ Department of Chemistry, Faculty of Science, University of Malaya, 50603 Kuala Lumpur, Malaysia \\ Correspondence should be addressed to M. Niyaz Khan; niyaz@um.edu.my
}

Received 20 May 2014; Accepted 9 September 2014; Published 13 November 2014

Academic Editor: Feng Ding

Copyright ( 2014 N. Abd. Razak and M. N. Khan. This is an open access article distributed under the Creative Commons Attribution License, which permits unrestricted use, distribution, and reproduction in any medium, provided the original work is properly cited.

\begin{abstract}
The values of the relative counterion $(X)$ binding constant $R_{X}^{\mathrm{Br}}\left(=K_{X} / K_{\mathrm{Br}}\right.$, where $K_{X}$ and $K_{\mathrm{Br}}$ represent cetyltrimethylammonium bromide, CTABr, micellar binding constants of $X^{v-}$ (in non-spherical micelles), $v=1,2$, and $\mathrm{Br}^{-}$(in spherical micelles)) are 58, 68,127 , and 125 for $X^{v-}=\mathbf{1}^{-}, \mathbf{1}^{2-}, \mathbf{2}^{-}$, and $\mathbf{2}^{2-}$, respectively. The values of $15 \mathrm{mM} \mathrm{CTABr} /\left[\mathrm{Na}_{v} X\right]$ nanoparticles-catalyzed apparent second-order rate constants for piperidinolysis of ionized phenyl salicylate at $35^{\circ} \mathrm{C}$ are $0.417,0.488,0.926$, and $0.891 \mathrm{M}^{-1} \mathrm{~s}^{-1}$ for $\mathrm{Na}_{v} X$ $=\mathrm{Na} 1, \mathrm{Na}_{2} 1, \mathrm{Na} 2$, and $\mathrm{Na}_{2} 2$, respectively. Almost entire catalytic effect of nanoparticles catalyst is due to the ability of nonreactive counterions, $X^{v-}$, to expel reactive counterions, $\mathbf{3}^{-}$, from nanoparticles to the bulk water phase.
\end{abstract}

\section{Introduction}

Research on nanoparticles has now become a cutting-edge area of chemical research [1]. Mono- and bilayer surfactant aggregates are nanoparticles which have been known for their characteristic physicochemical properties for more than 100 years [2]. The effects of surfactant aggregates/nanoparticles of different structural features on reaction rates have been extensively studied for the past nearly six decades [3-5]. These studies reveal very complex mechanistic aspects of micellar/nanoparticles catalysis of reaction rates [4-6]. Effects of counterionic salts on ionic surfactant as well as biomolecular structural transitions have been under extensive study since 1887 when Hofmeister first reported specific salt effects on the salting-out proteins [7]. But the mechanistic aspects of these specific salt effects are not yet fully understood [8-10].

Effects of inert salts of moderately hydrophobic counterions, such as benzoate and substituted benzoate ions, on ionic surfactant micellar growth have become very important for various industrial applications [9-11]. However, mechanistic details of such inert salt effects on ionic micellar growth are almost nonexistent. Effects of inert counterionic salts on pseudo-first-order rate constants $\left(k_{\text {obs }}\right)$ for the ionic surfactant nanoparticle-catalyzed semi-ionic bimolecular reactions, where ionic reactant is also a counterion, have been explained quantitatively by the use of pseudophase ion-exchange (PIE) model. But the use of PIE model involves mostly counterionic salts of highly and moderately hydrophilic counterions [12]. However, some inherent weaknesses of PIE model have been also realized $[13,14]$. The increase in $[\mathrm{MX}](\mathrm{MX}=3$ - and 4-FBzNa with $\mathrm{Bz}^{-}=\mathrm{C}_{6} \mathrm{H}_{4} \mathrm{CO}_{2}^{-}$) has caused nonlinear increase in $k_{\text {obs }}$ for piperidinolysis of anionic phenyl salicylate $\left(\mathrm{PSa}^{-}\right)$at a constant $[\mathrm{CTABr}]_{T} \gg \mathrm{cmc}$ where $[\mathrm{CTABr}]_{T}$ and $\mathrm{cmc}$ represent total concentration of cetyltrimethylammonium bromide and critical micelle concentration of CTABr, respectively [15]. The magnitudes of the gradient of the plot of $k_{\text {obs }}$ versus [MX] show continuous decrease with increasing [MX] [15]. The values of $k_{\text {obs }}$ remained almost independent of [MX] within its range where the presence of $5 \mathrm{mM} \mathrm{CTABr}$ resulted in more than 10 -fold increase in $k_{\text {obs }}$. Thus, $5 \mathrm{mM}$ $\mathrm{CTABr} /[\mathrm{MX}]$ nanoparticles act as catalyst because, in the absence of CTABr, the values of $k_{\text {obs }}$ remained independent of [MX] within its range covered in the study [15]. More than 10 -fold catalytic effects of CTABr/MX nanoparticles were not emphasized and discussed in the report [15]. The catalytic effects of CTABr $/ \mathrm{MX} / \mathrm{H}_{2} \mathrm{O}$ nanoparticles catalyst $(\mathrm{MX}=4$ methoxy and 4-methyl salicylates) on $k_{\mathrm{obs}}$ for piperidinolysis 


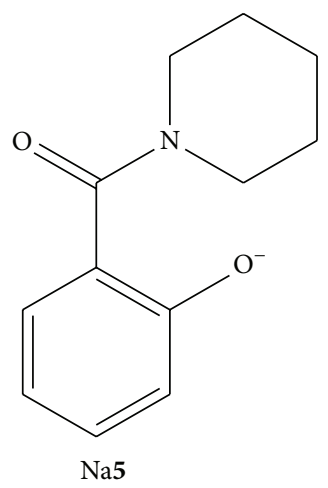

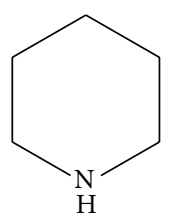<smiles>Oc1ccccc1</smiles>

6

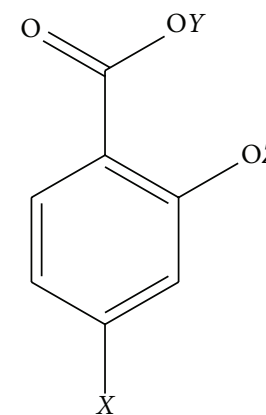

1H, $X=$ OMe, $Y=Z=H$

2H, $X=\mathrm{Me}, Y=Z=\mathrm{H}$

$3 \mathrm{H}, X=Z=\mathrm{H}, Y=\mathrm{C}_{6} \mathrm{H}_{5}$

Nal, $X=$ OMe, $Y=\mathrm{Na}^{+}, Z=\mathrm{H}$

$\mathrm{Na}_{2} \mathbf{1}, X=\mathrm{OMe}, Y=Z=\mathrm{Na}^{+}$

$\mathrm{Na} 2, X=\mathrm{Me}, Y=\mathrm{Na}^{+}, Z=\mathrm{H}$

$\mathrm{Na}_{2} 2, X=\mathrm{Me}, Y=Z=\mathrm{Na}^{+}$

$\mathrm{Na} 3, X=\mathrm{H}, Z=\mathrm{Na}^{+}, Y=\mathrm{C}_{6} \mathrm{H}_{5}$

Figure 1: Molecular structures of compounds $1 \mathbf{H}, \mathrm{Na} 1, \mathrm{Na}_{2} \mathbf{1}, \mathbf{2 H}, \mathrm{Na} 2, \mathrm{Na}_{2} \mathbf{2}, \mathbf{3 H}, \mathrm{Na} 3,4, \mathrm{Na}$, and 6.

of $\mathrm{PSa}^{-}$have been studied in the present study. The results and their probable explanations are described in this paper.

\section{Materials and Methods}

2.1. Materials. Reagent-grade 4-methoxysalicylic acid (1H), 4-methylsalicylic acid $(\mathbf{2 H})$, cetyltrimethylammonium bromide $(\mathrm{CTABr})$, phenyl salicylate $(3 \mathbf{H})$, and piperidine $(\mathbf{4})$ (Figure 1) were commercial products of highest available purity. Other common chemicals used were also of reagent grade. The stock solutions of $0.50 \mathrm{M} \mathrm{M}_{v} X\left(=\mathrm{Na}_{v} 1\right.$ and $\mathrm{Na}_{v} 2$ with $v=1$ and 2) were prepared by adding 0.52 and $1.25 \mathrm{M} \mathrm{NaOH}$ to the corresponding $0.50 \mathrm{M}$ solutions of $1 \mathrm{H}$ or $2 \mathrm{H}$. The stock solutions of $0.01 \mathrm{M} 3 \mathrm{H}$ were prepared in acetonitrile. Throughout the text, the symbol $[X]_{T}$ represents the total concentration of $X$.

2.2. Kinetic Measurements. The rate of $\mathrm{CTABr} / \mathrm{Na}_{v} X$ nanoparticles-catalyzed nucleophilic substitution reaction of $\mathbf{4}$ with $\mathrm{Na} 3$ was studied spectrophotometrically at $35^{\circ} \mathrm{C}$ by monitoring the disappearance of $\mathrm{Na} 3$ at 365 or $370 \mathrm{~nm}$. The products of the reaction of $\mathbf{4}$ with $\mathrm{Na} 3$ are sodium $\mathrm{N}$ piperidinyl salicylate (Na5) and phenol (6) (Figure 1). The details of the kinetic procedure and product characterization have been described elsewhere [16]. Absorbance values $\left(A_{\mathrm{ob}}\right)$ at different reaction time $(t)$ were found to fit to (1) for $\sim 8$ half-lives of the reactions. In (1), $\left[R_{0}\right]$ represents the initial concentration of $\mathbf{3 H}, \delta_{\text {ap }}$ is the apparent molar absorptivity of

$$
A_{\text {ob }}=\left[R_{0}\right] \delta_{\text {ap }} \exp \left(-k_{\text {obs }} t\right)+A_{\infty}
$$

the mixture, $k_{\mathrm{obs}}$ is the pseudo-first-order rate constant, and $A_{\infty}=A_{\text {obs }}$ at $t=\infty$. Throughout the study, the initial concentrations of $3 \mathbf{H}$ or $\mathrm{Na} 3$ were kept constant at $0.2 \mathrm{mM}$. The choice of this specific concentration was governed by the need to keep it sufficiently low so that it is less than the other salicylate counterions but high enough to measure the absorption spectrophotometrically.

\section{Results}

3.1. Effects of $\left[\mathrm{Na}_{v} \mathrm{X}\right](v=1,2)$ on $k_{o b s}$ for the Reaction of 4 with $\mathrm{Na3}$ at a Constant $[\mathrm{CTABr}]_{T}$ and $35^{\circ} \mathrm{C}$. A series of

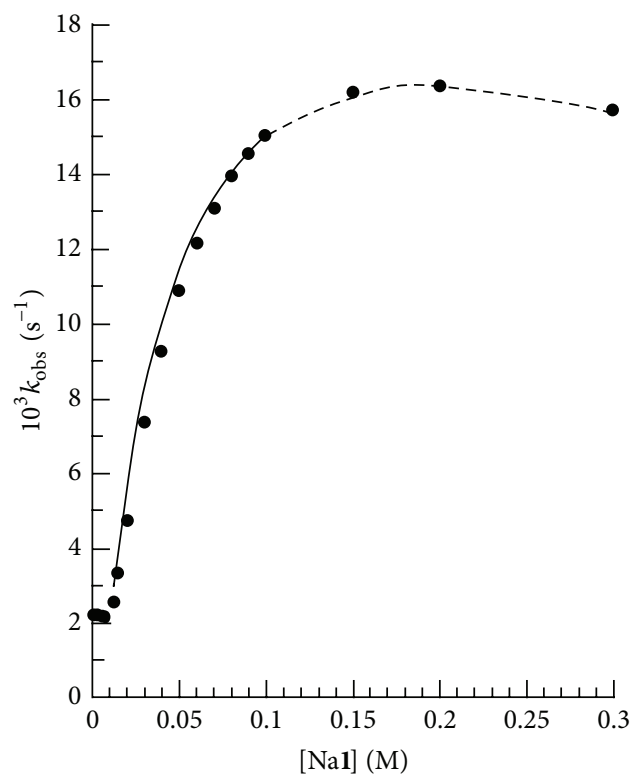

FIGURE 2: Plots showing the dependence of $k_{\mathrm{obs}}$ upon [Na1] for piperidinolysis of $3 \mathrm{H}$ at $0.2 \mathrm{mM} 3 \mathrm{H}, 0.1 \mathrm{M} 4,0.03 \mathrm{M} \mathrm{NaOH}$, and $35^{\circ} \mathrm{C}$. The solid line is drawn through the calculated data points using (2) with kinetic parameters $\left(k_{\text {cat }}\right.$ and $\left.K^{X / s}\right)$, listed in Table 2. The dotted line is drawn through the predicted data points assuming the presence of $\mathrm{WM}$ at $[\mathrm{Na} 1]_{0}^{\mathrm{op}}<[\mathrm{Na} 1] \leq 300 \mathrm{mM}$.

kinetic runs was carried out at the constant $15 \mathrm{mM} \mathrm{CTABr}$, $0.2 \mathrm{mM} 3 \mathrm{H}, 0.1 \mathrm{M} 4$, and varying values of $\left[\mathrm{Na}_{v} X\right](v=1,2)$ within the range $0 \leq\left[\mathrm{Na}_{v} X\right] \leq 0.30 \mathrm{M}$ for $\mathrm{Na}_{v} X=\mathrm{Na}_{v} 1$ $(v=1,2)$. The values of $k_{\text {obs }}$ versus $\left[\mathrm{Na}_{v} \mathbf{1}\right]$ at $[\mathrm{NaOH}] /[\mathbf{1 H}]=$ 1.04 are shown in Figure 2. Similar plot of $k_{\text {obs }}$ versus $\left[\mathrm{Na}_{v} 1\right]$ was also obtained at $[\mathrm{NaOH}] /\left[\mathrm{Na}_{v} 1\right]=2.50$. The plot of Figure 2 shows initial segment where the values of $k_{\text {obs }}$ are almost independent of $\left[\mathrm{Na}_{v} \mathbf{1}\right]$ at the initial low values of $\left[\mathrm{Na}_{v} \mathbf{1}\right]$ followed by the segment where the values of $k_{\text {obs }}$ reveal monotonic increase of more than 7 -fold with the increase in $\left[\mathrm{Na}_{v} 1\right]$.

The values of $k_{\text {obs }}$ were also obtained at constant $15 \mathrm{mM}$ $\mathrm{CTABr}, 35^{\circ} \mathrm{C}, 0.2 \mathrm{mM} 3 \mathrm{H}, 0.1 \mathrm{M} \mathrm{4}$, and different values of $\left[\mathrm{Na}_{v} 2\right](v=1,2)$ within the range $0 \leq\left[\mathrm{Na}_{v} 2\right] \leq 0.30 \mathrm{M}$. The values of $k_{\text {obs }}$ versus $\left[\mathrm{Na}_{v} 2\right]$, at $[\mathrm{NaOH}] /[2 \mathrm{H}]=1.04$, are 
TABLE 1: The values of $\delta_{\text {ap }}$, calculated from (1) for the piperidinolysis of $\mathbf{3}^{-}$under the variety of experimental conditions ${ }^{\mathrm{a}}$.

\begin{tabular}{|c|c|c|c|c|c|c|}
\hline \multirow{2}{*}[\mathrm{Na}_{v}X]{$^{\mathrm{b}}(\mathrm{mM})$} & \multicolumn{4}{|c|}{$10^{-1} \delta_{\mathrm{ap}}\left(\mathrm{M}^{-1} \mathrm{~cm}^{-1}\right)$} & \multirow{2}{*}{$\mathrm{CH}_{3} \mathrm{CN}(\% \mathrm{v} / \mathrm{v})$} & \multirow{2}{*}{$10^{-1} \delta_{\mathrm{ap}}\left(\mathrm{M}^{-1} \mathrm{~cm}^{-1}\right)^{\mathrm{e}}$} \\
\hline & $\mathrm{Nal}^{\mathrm{c}}$ & $\mathrm{Na}_{2} \mathbf{1}^{\mathrm{d}}$ & $\mathrm{Na} 2^{\mathrm{c}}$ & $\mathrm{Na}_{2} 2^{\mathrm{d}}$ & & \\
\hline 0 & $373 \pm 2^{f}$ & $369 \pm 1^{\mathrm{f}}$ & $366 \pm 2^{f}$ & $3372 \pm 1^{\mathrm{f}}$ & 2 & $175 \pm 1^{\mathrm{f}}$ \\
\hline 10 & $380 \pm 2$ & $379 \pm 1$ & $407 \pm 3$ & $386 \pm 1$ & 25 & $215 \pm 1$ \\
\hline 15 & $356 \pm 1$ & $362 \pm 1$ & $341 \pm 1$ & $343 \pm 1$ & 50 & $250 \pm 1$ \\
\hline 30 & $323 \pm 1$ & $330 \pm 1$ & $403 \pm 8$ & $395 \pm 15$ & 60 & $265 \pm 2$ \\
\hline 50 & $286 \pm 1$ & $292 \pm 2$ & $457 \pm 5$ & $364 \pm 6$ & 70 & $288 \pm 1$ \\
\hline 70 & $276 \pm 2$ & $275 \pm 2$ & $236 \pm 1$ & $250 \pm 1$ & 84 & $300 \pm 3$ \\
\hline 100 & $251 \pm 1$ & $276 \pm 1$ & $240 \pm 1$ & $230 \pm 4$ & 90 & $367 \pm 3$ \\
\hline 150 & $239 \pm 1$ & $257 \pm 1$ & $222 \pm 1$ & $227 \pm 1$ & 92 & $435 \pm 3$ \\
\hline 200 & $230 \pm 1$ & $251 \pm 1$ & $222 \pm 2$ & $226 \pm 1$ & & \\
\hline 300 & $219 \pm 1$ & $244 \pm 1$ & $221 \pm 2$ & $238 \pm 2$ & & \\
\hline
\end{tabular}

${ }^{\mathrm{a}}[3 \mathrm{H}]_{0}=0.2 \mathrm{mM}, \lambda=370 \mathrm{~nm}, 35^{\circ} \mathrm{C}, 30 \mathrm{mM} \mathrm{NaOH}, 100 \mathrm{mM} \mathrm{Pip}$, and $15 \mathrm{mM} \mathrm{CTABr} .{ }^{\mathrm{b}} \mathrm{Na}_{v} X=\mathrm{Na}_{v} \mathbf{1}$ and $\mathrm{Na}_{v} 2, v=1,2 .{ }^{\mathrm{c}}[\mathrm{NaOH}] /[\mathrm{XH}]=1.04 .{ }^{\mathrm{d}}[\mathrm{NaOH}] /[\mathrm{XH}]$ $=2.50 .{ }^{\mathrm{e}}$ Calculated from (1) by the use of observed data $\left(A_{\mathrm{ob}}\right.$ versus reaction time $\left.t\right)$ obtained for the kinetic runs at $0.2 \mathrm{mM} 3 \mathrm{H}, 10 \mathrm{mM} \mathrm{NaOH}, 100 \mathrm{mM}$ Pip, $370 \mathrm{~nm}$, and $35^{\circ} \mathrm{C}$ and within $\mathrm{CH}_{3} \mathrm{CN}$ content range of $2-92 \% \mathrm{v} / \mathrm{v}$ in mixed aqueous solvents. ${ }^{\mathrm{f}}$ Error limits are standard deviations.

shown in Figure 3. Similar plot of $k_{\mathrm{obs}}$ versus $\left[\mathrm{Na}_{v} 2\right]$ (not shown) was also obtained at $[\mathrm{NaOH}] /[\mathbf{2 H}]=2.5$. The values of $[\mathrm{NaOH}]$ were varied from 0.030 to $\leq 0.18 \mathrm{M}$ under the experimental conditions of entire kinetic runs for both $\mathrm{Na}_{v} 1$ and $\mathrm{Na}_{v}$. The shape of the plot of Figure 3 is similar to that of Figure 2 when $\left[\mathrm{Na}_{v} 2\right] \leq \sim 20 \mathrm{mM}$. The increase in $\left[\mathrm{Na}_{v} 2\right]$ at $\sim 20 \mathrm{mM} \mathrm{Na}_{v} 2$ reveals a mild increase followed by a decrease and then increase again in the values of $k_{\text {obs }}$ (Figure 3). Similar break in the plot (not shown) of $k_{\text {obs }}$ versus $\left[\mathrm{Na}_{v} 2\right]$ was also obtained at $[\mathrm{NaOH}] /[2 \mathrm{H}]=2.5$. These observations may be attributed to the change in the structure of $\mathrm{Na}_{v} X / \mathrm{CTABr}$ nanoparticles to some higher interfacial curvature structures such as curved bilayer structures at $\sim 20 \mathrm{mM} \mathrm{Na}_{v} 2$ [17].

The absence and presence of break in the monotonic plot of respective Figures 2 and 3 are indirectly supported by the following observations. The values of $\delta_{\text {ap }}$, obtained for piperidinolysis of $3^{-}$at $10 \mathrm{mM} \mathrm{NaOH}, 100 \mathrm{mM}$ Pip, $0.2 \mathrm{mM}$ $3 \mathrm{H}, 35^{\circ} \mathrm{C}$, and $370 \mathrm{~nm}$, increase nonlinearly from 1750 to $4350 \mathrm{M}^{-1} \mathrm{~cm}^{-1}$ with the increase in $\mathrm{CH}_{3} \mathrm{CN}$ content from 2 to $92 \% \mathrm{v} / \mathrm{v}$ in mixed aqueous solvent (Table 1). The values of $\delta_{\text {ap }}$, obtained for piperidinolysis of $\mathbf{3}^{-}$at $30 \mathrm{mM} \mathrm{NaOH}$, $100 \mathrm{mM}$ Pip, $0.2 \mathrm{mM} 3 \mathrm{H}, 35^{\circ} \mathrm{C}, 370 \mathrm{~nm}$, and different values of $\left[\mathrm{Na}_{v} \mathrm{X}\right]$, for $\mathrm{Na}_{v} 1$ and $\mathrm{Na}_{v} 2(v=1,2)$, are also summarized in Table 1. It is evident from Table 1 that (a) the values of $\delta_{\text {ap }}$ are almost independent of $\left[\mathrm{Na}_{v} X\right]$ within its range $0-\sim 15 \mathrm{mM}$ for $X=\mathbf{1}^{v-}$ and $0-\sim 50 \mathrm{mM}$ for $X=2^{v-}$ and (b) the values of $\delta_{\text {ap }}$ reveal a monotonic decrease with increasing $\left[\mathrm{Na}_{v} 1\right], v=1,2$, within its range $\sim 30-300 \mathrm{mM}$. But the values of $\delta_{\text {ap }}$ show a sharp decrease with the increase in $\left[\mathrm{Na}_{v} 2\right], v=1,2$, from 50 to $70 \mathrm{mM}$ and then become almost independent of [ $\left.\mathrm{Na}_{v} 2\right]$ within its range $\sim 70-300 \mathrm{mM}$. These observations simply demonstrate that $\mathrm{Na}_{v} X$-induced $\mathrm{CTABr} / \mathrm{Na}_{v} X$ nanoparticles structural transition, within $\left[\mathrm{Na}_{v} X\right]$ range of $50-300 \mathrm{mM}$, is not the same for $\mathrm{Na}_{v} \mathbf{1}$ and $\mathrm{Na}_{v} 2(v=1,2)$.

3.2. Effects of $\left[N a_{v} X\right]$ on $k_{o b s}$ for the Reaction of 4 with $\mathrm{Na} 3$ in the Absence of $C T A B r$ at $35^{\circ} \mathrm{C}$. In order to quantify the catalytic effects of CTABr $/ \mathrm{Na}_{v} X$ nanoparticles on the rate of

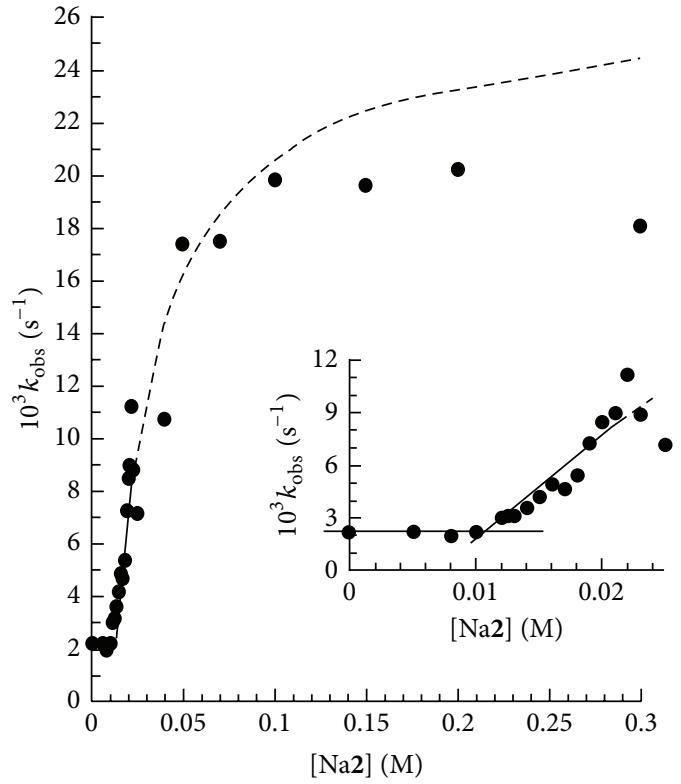

FIGURE 3: Plot showing the dependence of $k_{\mathrm{obs}}$ upon [Na2], for piperidinolysis of $3 \mathrm{H}$ at $0.2 \mathrm{mM} \mathrm{PSa}^{-}, 0.1 \mathrm{M} \mathrm{4}, 0.03 \mathrm{M} \mathrm{NaOH}$, and $35^{\circ} \mathrm{C}$. The solid line is drawn through the calculated data points using (2) with kinetic parameters $\left(k_{\text {cat }}\right.$ and $\left.K^{X / S}\right)$, listed in Table 2. The dotted line is drawn through the predicted data points assuming the presence of WM at $[\mathrm{Na} 2]_{0}^{\mathrm{op}}<[\mathrm{Na} 2] \leq 300 \mathrm{mM}$.

piperidinolysis of $\mathrm{Na} 3$, it is essential to study the effects of $\left[\mathrm{Na}_{v} \mathrm{X}\right]$ on $k_{\text {obs }}$ at $35^{\circ} \mathrm{C}$ and $[\mathrm{CTABr}]_{T}=0$. Although benzoate and substituted benzoate ions are nonreactive towards the nucleophilic cleavage of $\mathrm{Na} 3$, such inert salts might affect $k_{\mathrm{obs}}$ through ionic strength effect or specific salt effect. Thus, a series of kinetic runs was carried out at $0.2 \mathrm{mM} \mathrm{3H}, 0.1 \mathrm{M} \mathrm{4}$, $30 \mathrm{mM} \mathrm{NaOH}$, and varying values of $\left[\mathrm{Na}_{v} 1\right]$ and $\left[\mathrm{Na}_{v} 2\right]$. The values of $k_{\text {obs }}$ reveal $<12 \%$ decrease within $\left[\mathrm{Na}_{v} 1\right]$ or $\left[\mathrm{Na}_{v} 2\right]$ range of $0-100 \mathrm{mM}$ at $[\mathrm{NaOH}] /\left[\mathrm{Na}_{v} \mathbf{1}\right]=1.04$ and $0-150 \mathrm{mM}$ at $[\mathrm{NaOH}] /\left[\mathrm{Na}_{v} 1\right]$ or $\left[\mathrm{Na}_{v} 2\right]=2.5$. 


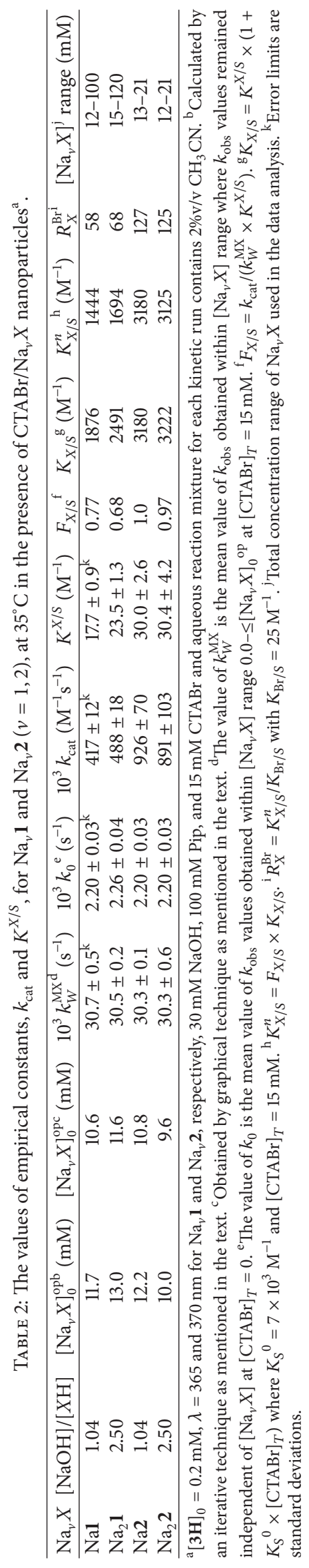




\section{Discussion}

The experimental data $\left(k_{\mathrm{obs}}\right.$ versus $\left.\left[\mathrm{Na}_{v} X\right]\right)$ exhibited by Figures 2 and 3 (at $\left[\mathrm{Na}_{v} 2\right]<\sim 21 \mathrm{mM}$ ) were found to fit to empirical equation:

$$
k_{\mathrm{obs}}=\frac{k_{0}+k_{\mathrm{cat}}\left(\left[\mathrm{Na}_{v} X\right]-\left[\mathrm{Na}_{v} X\right]_{0}^{\mathrm{op}}\right)}{1+K^{X / S}\left(\left[\mathrm{Na}_{v} X\right]-\left[\mathrm{Na}_{v} X\right]_{0}^{\mathrm{op}}\right)},
$$

where $k_{\text {cat }}$ and $K^{X / S}$ are empirical constants, $k_{0}=k_{\text {obs }}$ at $\left[\mathrm{Na}_{v} X\right]-\left[\mathrm{Na}_{v} X\right]_{0}^{\text {op }}=0$, and $\left[\mathrm{Na}_{v} X\right]_{0}^{\text {op }}$ represents the optimum concentration of $\mathrm{Na}_{v} X$ below which the values of $k_{\mathrm{obs}}$ are independent of $\left[\mathrm{Na}_{v} X\right]$. The empirical constant $k_{\text {cat }}$ represents $15 \mathrm{mM} \mathrm{CTABr} /\left[\mathrm{Na}_{v} X\right]$ nanoparticles-catalyzed apparent second-order rate constant for piperidinolysis of Na3. The values of $\left[\mathrm{Na}_{v} X\right]_{0}^{\text {op }}$ were calculated using an iterative technique as described elsewhere [15]. These values of $\left[\mathrm{Na}_{v} \mathrm{X}\right]_{0}^{\mathrm{op}}$ (Table 2) are comparable with the corresponding values of $\left[\mathrm{Na}_{v} X\right]_{0}^{\text {op }}$ obtained by the graphical technique [5]. As described in detail elsewhere $[15,18]$, the value of $\left[\mathrm{Na}_{v} X\right]_{0}^{\text {op }}$ represents the optimum value of $\left[\mathrm{Na}_{v} X\right]$ required for the occurrence of ion exchange processes $X^{-} / \mathrm{OH}^{-}$and $X^{-} / \mathrm{Br}^{-}$. Equation (2), with replacement of $k_{\text {cat }}$ by $\theta K^{X / S}$ where $\theta$ is an empirical constant, has been found to explain quantitatively similar observed data $\left(k_{\text {obs }}\right.$ versus $\left.\left[\mathrm{Na}_{v} X\right]\right)$, for different $\mathrm{Na}_{v} X$ [5]. The nonlinear least-squares technique was used to calculate $k_{\text {cat }}$ and $K^{X / S}$ from (2) by considering $k_{0}$ as a known parameter. The least-squares calculated values of $k_{\text {cat }}$ and $K^{X / S}$ and experimentally determined values of $k_{0}$, at $[\mathrm{NaOH}] /[X \mathrm{H}]=1.04$ and 2.50 , are shown in Table 2 . The statistical reliability of the observed data fit to (2) is evident from the standard deviations associated with the calculated values of $k_{\text {cat }}$ and $K^{X / S}$ as well as from the solid line plots of Figures 2 and 3 which were drawn through the least-squares calculated data points.

It has been described in detail elsewhere $[5,15,18]$ that the nonlinear increase in $k_{\text {obs }}$ with the increase of $\left[\mathrm{Na}_{v} X\right]$ at a constant $[\mathrm{CTABr}]_{T}$ is due to the transfer of micellized $3^{-}$ (i.e., $3^{-}$with subscript $M$ indicating micellar pseudophase) to aqueous phase (i.e., $3^{-}{ }_{W}$ with subscript $W$ indicating bulk water phase) through the occurrence of ion exchange process $X^{v-} / 3^{-}$. This is due to the reason that the value of $k_{\mathrm{obs}}$ is more than 10-fold larger in the bulk water phase than that in the micellar pseudophase as evident from the listed values of $k_{W}^{\mathrm{MX}}$ and $k_{0}$ in Table 2 . The occurrence of ion exchange $X^{v-} / 3^{-}$in the related reaction systems [5] has been found to decrease the CTABr micellar binding constant $\left(K_{S}\right)$ of $3^{-}$with the increasing $\left[\mathrm{Na}_{v} X\right]$ through an empirical relationship:

$$
K_{S}=\frac{K_{S}^{0}}{\left(1+K_{X / S}\left[\mathrm{Na}_{v} X\right]\right)},
$$

where $K_{S}^{0}=K_{S}$ at $\left[\mathrm{Na}_{v} X\right]=0$ and $K_{X / S}$ represents an empirical constant whose magnitude is the measure of the ability of counterion $X^{v-}$ to expel another counterion $S^{-}$from the cationic micellar pseudophase to the bulk aqueous phase through the occurrence of ion exchange process $X^{v-} / S^{-}$at the cationic micellar surface. It can be easily shown that the reaction mechanism for nucleophilic reaction of 4 with $3^{-}$, expressed in terms of pseudophase micellar (PM) model and (3), can lead to (2) [18] with $k_{\text {cat }}$ and $K^{X / S}$ expressed by (4) and (5), respectively. As shown in the following equation, $k_{W}^{\mathrm{MX}}=$ $k_{\text {obs }}\left[\mathrm{Na}_{v} X\right] k_{\text {obs }}\left[\mathrm{Na}_{v} X\right] F_{X / S}$ is an

$$
k_{\text {cat }}=F_{X / S} k_{W}^{\mathrm{MX}} K^{X / S} \text {, }
$$

$k_{W}^{\mathrm{MX}}=k_{\text {obs }}$ obtained within $\left[\mathrm{Na}_{v} X\right]$ range where $k_{\text {obs }}$ values are independent of $\left[\mathrm{Na}_{v} X\right]$ in the absence of CTABr and $F_{X / S}$ is an empirical constant whose magnitude should vary in the range $>0.0$ to $\leq 1.0$ [18]. The following equation

$$
K^{X / S}=\frac{K_{X / S}}{\left(1+K_{S}^{0}[\mathrm{CTABr}]_{T}\right)}
$$

is valid only under the experimental conditions where $[\mathrm{CTABr}]_{T}-\mathrm{cmc} \approx[\mathrm{CTABr}]_{T}$ with $\mathrm{cmc}$ representing critical micelle concentration of CTABr. Perhaps, it is worth mentioning that the value of $\mathrm{cmc}$ of CTABr, at $0.2 \mathrm{mM} \mathrm{3}^{-}$and $\left[\mathrm{Na}_{v} X\right]=0$, was kinetically determined as $0.09 \mathrm{mM}$ which became $0.04 \mathrm{mM}$ at $0.1 \mathrm{M} \mathrm{NaBr}$. The value of $\mathrm{cmc}$ became $\sim 0$ at $\geq 0.5 \mathrm{M} \mathrm{NaBr}$ [19]. These observations demonstrate that the value of $\mathrm{cmc}$ is negligible compared with $[\mathrm{CTABr}]_{T}$ at its value of $\geq 5 \mathrm{mM}$.

The value of $F_{X / S}$ measures the fraction of the micellized counterions $\left(3_{M}^{-}\right)$transferred to aqueous phase by the optimum concentration of $\mathrm{Na}_{v} X$ through ion exchange $X^{v-} / 3^{-}$ [18]. The value of $F_{X / S}$ was calculated from (4) by the use of listed values of $k_{\text {cat }}, k_{W}^{\mathrm{MX}}$, and $K^{X / S}$ in Table 2 and these calculated values of $F_{X / S}$ for $\mathrm{Na} 1, \mathrm{Na}_{2} 1, \mathrm{Na} 2$, and $\mathrm{Na}_{2} 2$ are also listed in Table 2. The value of $K_{X / S}$ was calculated from (5) with the reported value of $K_{S}^{0}\left(=7 \times 10^{3} \mathrm{M}^{-1}[5,15]\right)$. The calculated values of $K_{X / S}$ for $\mathrm{Na}_{v} X$ with $v=1,2$ and $X=1,2$ are shown in Table 2. It has been concluded elsewhere $[5,18]$ that the normalized $K_{X / S}^{n}\left(=F_{X / S} K_{X / S}\right)$ and $K_{Y / S}^{n}\left(=F_{Y / S} K_{X / S}\right)$ values are empirically related to the ratio $K_{X} / K_{Y}$ through the relationship $R_{X}^{Y}=K_{X} / K_{Y}=K_{X / S}^{n} / K_{Y / S}^{n}$ where $K_{X}=\left[X_{M}\right] /\left(\left[X_{W}\right]\left[D_{n}\right]\right)$ and $K_{Y}=\left[Y_{M}\right] /\left(\left[Y_{W}\right]\left[D_{n}\right]\right)$. The symbols $K_{X}$ and $K_{Y}$ represent CTABr micellar binding constants of counterions $X^{-}$and $Y^{-}$, respectively, and $\left[D_{n}\right]$ is the concentration of CTABr micelles with each micelle containing $n$ number of monomers. The values of $K_{X / S}^{n}$ (Table 2) and the reported value of $25 \mathrm{M}^{-1}[15,18]$ for $K_{\mathrm{Br} / S}^{n}$ (with $\mathrm{Br}^{-}=\mathrm{Y}^{-}$) give the values of $R_{X}^{\mathrm{Br}}$ for $X=\mathbf{1}^{v-}, 2^{v-}$ with $v=1$ and 2 . These results are also shown in Table 2. It is relevant to note that the value of $K_{\mathrm{Br} / S}^{n}\left(=25 \mathrm{M}^{-1}\right)$ is derived from kinetic parameters obtained in the presence of spherical CTABr micelles (SM). But the values of $K_{X / S}^{n}$ may be derived in the presence of either SM or nonspherical micelles (NSM such as wormlike micelles, WM, or vesicles, Vs). Thus, $R_{X}^{\mathrm{Br}}$ becomes conventional ion exchange constant $\left(K_{X}^{\mathrm{Br}}\right)$ if the value of $K_{X / S}^{n}$ is also obtained in the presence of SM.

The value of $R_{X}^{\mathrm{Br}}(=68)$ for $X=\mathbf{1}^{-}$may be compared with the $R_{X}^{\mathrm{Br}}(=89)$ obtained at $[\mathrm{NaOH}] /[X \mathrm{H}]=2.1$ for $X$ representing 5-methoxysalicylate dianion [20]. The reported values of $R_{X}^{\mathrm{Br}}$ for $X=$ salicylate dianion, benzoate ion, and 
4-methoxybenzoate ion are 44,5.6, and 5.2, respectively [20]. It is evident from the literature that the aqueous solutions of CTABr $/ M_{v} X$ containing $\leq 15 \mathrm{mM} \mathrm{CTABr}$ and $12 \mathrm{mM} \leq\left[M_{v} X\right] \leq 22 \mathrm{mM}$ exhibited the presence of SM for $M_{v} X=$ sodium benzoate [21] and $\mathrm{WM}$ for $M_{v} X=$ sodium salicylate [22], sodium 3-, 4-, and 5-methyl salicylate [23], and $\mathrm{Na}_{v} \mathbf{1}, \mathrm{Na}_{v} 2$ where $v=1,2$. These observations cannot be explained in terms of Hammett substituent constants $\left(\sigma_{H}, \sigma_{4-\mathrm{OMe}}\right)$. These observations reveal that the shapes and sizes of the aqueous $\mathrm{CTABr} / M_{v} X$ nanoparticles depend apparently upon the magnitudes of $R_{X}^{\mathrm{Br}}$. The magnitude of $R_{X}^{\mathrm{Br}}$ is apparently governed by the combined effects of steric requirements and hydrophilic and hydrophobic interactions of counterion $X^{-}$with cationic headgroup. Hydrophilic interaction includes ion-ion, ion-dipole, dipoledipole, and inter- and intramolecular hydrogen-bonding interactions.

The values of $k_{\text {cat }}$ versus $R_{X}^{\mathrm{Br}}$ (Table 2) reveal a linear relationship with intercept $=0$ and slope $=(7.20 \pm 0.07)$ $\times 10^{-3} \mathrm{M}^{-1} \mathrm{~s}^{-1}$. This observation implies that almost entire catalytic effect of CTABr/ $/ \mathrm{Na}_{v} X$ nanoparticles catalyst is due to the ability of nonreactive counterions $X^{v-}$ to expel the reactive counterions $3^{-}$from $\mathrm{CTABr} / \mathrm{Na}_{v} X$ nanoparticles to the bulk water phase.

Apparent maximum catalytic constant $\left(\mu_{\mathrm{ap}}\right)$ of $15 \mathrm{mM}$ $\mathrm{CTABr} /\left[\mathrm{Na}_{v} X\right]$ nanoparticle catalyst may be obtained from the relationship: $\mu_{\text {ap }}=k_{\text {cat }} / k_{0}$ and such calculated values of $\mu_{\text {ap }}$ are 190, (216), 421, and $\left(405 \mathrm{M}^{-1}\right)$ for respective Nal, $\mathrm{Na}_{2} 1, \mathrm{Na} 2$, and $\mathrm{Na}_{2} 2$ where parenthesized values represent at $[\mathrm{NaOH}] /[X \mathrm{H}]=2.5$ (i.e., for $\mathrm{Na}_{2} 1$ and $\mathrm{Na}_{2} 2$ ). The estimated value of the second-order rate constant $\left(k_{M}^{2}\right)$ for the reaction of 4 with $3^{-}$in the CTABr micellar pseudophase (i.e., aqueous CTABr nanoparticles), at $\left[\mathrm{Na}_{v} X\right]=0$, is $3.4 \times 10^{-3} \mathrm{M}^{-1} \mathrm{~s}^{-1}$ [19]. Thus, the real maximum catalytic constants $\left(\mu_{\text {real }}\right)$ may be obtained from the relationship: $\mu_{\text {real }}=k_{\text {cat }}^{\prime} / k_{M}^{2}$ where $k_{\text {cat }}^{\prime}$ $=k_{\text {cat }} /[$ Pip $]$ (with $[\mathrm{Pip}]=0.1 \mathrm{M}$ ). The calculated values of $\mu_{\text {real }}$ are $1230,(1440), 2720$, and $\left(2620 \mathrm{M}^{-1}\right)$ for respective Nal, $\mathrm{Na}_{2} 1, \mathrm{Na} 2$, and $\mathrm{Na}_{2} 2$ where parenthesized values represent at $[\mathrm{NaOH}] /[\mathrm{XH}]=2.5$.

The values of $k_{\text {cat }}$ and $R_{X}^{\mathrm{Br}}$ for $\mathrm{NaX}$ are not significantly different from the corresponding values for $\mathrm{Na}_{2} X$ for $X=\mathbf{1}$ and 2 (Table 2). These results reveal that energetically favorable electrostatic interaction is apparently insignificant compared with hydrophobic interaction between counterions, $X^{\nu-}$, and aqueous cationic interface of $\mathrm{CTABr} / \mathrm{Na}_{v} X$ nanoparticles. Perhaps, this is the first quantitative explanation of the earlier qualitative experimental observation that sodium salicylate and salicylic acid are equally effective in driving the micellar structural transition SM-to-WM at a constant temperature [23]. The aqueous structure of $\mathrm{CTABr} / \mathrm{Na}_{v} X$ nanoparticles remains WM at $35^{\circ} \mathrm{C}, \leq 15 \mathrm{mM} \mathrm{CTABr}$ and $12 \mathrm{mM} \leq\left[\mathrm{Na}_{v} X\right]$ $\leq \sim 22 \mathrm{mM}$ for $\mathrm{Na}_{v} X=\mathrm{Na}_{v} 1$ and $\mathrm{Na}_{v} 2(v=1,2)$. But the values of $k_{\text {cat }}$ are $\sim 2$-fold larger for $\mathrm{Na}_{v} 2$ than those for $\mathrm{Na}_{v} 1$ (Table 2). Thus, it is apparent that a quantitative correlation between $k_{\text {cat }}$ and $R_{X}^{\mathrm{Br}}$ is better than that between $k_{\text {cat }}$ and the aqueous structures of CTABr $/ \mathrm{Na}_{v} X$ nanoparticles where rheologically assigned structures remain the same (WM) for both $\mathrm{Na}_{v} 1$ and $\mathrm{Na}_{v} 2$ at $<22 \mathrm{mM} \mathrm{Na}_{v} X$.

\section{Conclusions}

The linear plot of $k_{\text {cat }}$ versus $R_{X}^{\mathrm{Br}}$ with essentially zero intercept reveals indirectly that the catalytic efficiency of $\mathrm{CTABr} / \mathrm{Na}_{v} \mathrm{X} / \mathrm{H}_{2} \mathrm{O}$ nanoparticles catalyst is almost entirely due to the ability of nonreactive counterions, $X^{v-}$, to expel reactive counterions, $\mathbf{3}^{-}$from nanoparticles to the bulk water phase. Binding affinity of counterions, $X^{-}$and $X^{2-}$, with $\mathrm{CTABr} / \mathrm{Na}_{v} X / \mathrm{H}_{2} \mathrm{O}$ nanoparticles (measured by the magnitude of $R_{X}^{\mathrm{Br}}$ ) remains nearly unchanged for $X=\mathbf{1}$ and 2 . The polarity of the CTABr $/ \mathrm{Na}_{v} X / \mathrm{H}_{2} \mathrm{O}$ nanoparticles-bound $3^{-}$is not the same for $X^{v-}=\mathbf{1}^{v-}$ and $\mathbf{2}^{v-}, v=1,2$, within $\left[\mathrm{Na}_{v} X\right]$ range of $\sim 70-300 \mathrm{mM}$.

\section{Conflict of Interests}

The authors declare that there is no conflict of interests regarding the publication of this paper.

\section{Acknowledgment}

This research is supported by UM High Impact Research Grant UM-MOHE UM.C/625/1/HIR/MOHE/SC/07 from the Ministry of Higher Education, Malaysia.

\section{References}

[1] P. J. Stang, "Abiological self-assembly via coordination: formation of 2D metallacycles and 3D metallacages with well-defined shapes and sizes and their chemistry," Journal of the American Chemical Society, vol. 134, no. 29, pp. 11829-11830, 2012.

[2] F. M. Menger, “The structure of micelles," Accounts of Chemical Research, vol. 12, no. 4, pp. 111-117, 1979.

[3] J. H. Fendler and E. J. Fendler, Catalysis in Micellar and Macromolecular Systems, Academic Press, New York, NY, USA, 1975.

[4] J. H. Fendler, Membrane Mimetic Chemistry, Wiley-Interscience, New York, NY, USA, 1982.

[5] M. N. Khan, Micellar Catalysis, vol. 133 of Surfactant Science Series, chapter 3 and references cited therein, CRC Press, Taylor \& Francis Group, Boca Raton, Fla, USA, 2006.

[6] C. A. Bunton and G. Savelli, "Organic reactivity in aqueous micelles and similar assemblies," Advances in Physical Organic Chemistry, vol. 22, pp. 213-309, 1987.

[7] F. Hofmeister, "About regularities in the protein precipitating effects of salts and the relation of these effects with physiological behavior of salts," Archiv für Experimentelle Pathologie und Pharmakologie, vol. 24, pp. 247-260, 1887.

[8] D. F. Parsons, M. Boström, P. L. Nostro, and B. W. Ninham, "Hofmeister effects: interplay of hydration, nonelectrostatic potentials, and ion size," Physical Chemistry Chemical Physics, vol. 13, no. 27, pp. 12352-12367, 2011.

[9] P. Jungwirth and D. J. Tobias, "Specific ion effects at the air/water interface," Chemical Reviews, vol. 106, no. 4, pp. 1259-1281, 2006.

[10] L. S. Romsted, "Do amphiphile aggregate morphologies and interfacial compositions depend primarily on interfacial hydration and ion-specific interactions? The evidence from chemical trapping," Langmuir, vol. 23, no. 2, pp. 414-424, 2007.

[11] Y. Qi and J. L. Zakin, "Chemical and rheological characterization of drag-reducing cationic surfactant systems," Industrial 
and Engineering Chemistry Research, vol. 41, no. 25, pp. 63266336, 2002.

[12] L. S. Romsted, "Micellar effects on reaction rates and equilibria," in Surfactants in Solutions, K. L. Mittal and B. Lindman, Eds., vol. 2, pp. 1015-1068, Plenum, New York, NY, USA, 1984.

[13] R. Germani, G. Savelli, T. Romeo, N. Spreti, G. Cerichelli, and C. A. Bunton, "Micellar head group size and reactivity in aromatic nucleophilic substitution," Langmuir, vol. 9, no. 1, pp. 55-60, 1993.

[14] M. N. Khan, "Mechanism of catalysis in micellar systems," in Encyclopedia of Surface and Colloid Science, A. T. Hubbard, Ed., pp. 3178-3191, Marcel Dekker, New York, NY, USA, 2002.

[15] N. S. M. Yusof and M. N. Khan, "Determination of an ion exchange constant by the use of a kinetic probe: a new semiempirical kinetic approach involving the effects of 3-F- and 4-Fsubstituted benzoates on the rate of piperidinolysis of anionic phenyl salicylate in aqueous cationic micelles," Langmuir, vol. 26, no. 13, pp. 10627-10635, 2010.

[16] M. N. Khan and S. Y. Kun, "Effects of organic salts on the rate of intramolecular general base-catalyzed piperidinolysis of ionized phenyl salicylate in the presence of cationic micelles," Journal of the Chemical Society, Perkin Transactions 2, no. 8, pp. 1325-1330, 2001.

[17] L. Brinchi, R. Germani, L. Goracci, G. Savelli, and C. A. Bunton, "Decarboxylation and dephosphorylation in new gemini surfactants. Changes in aggregate structures," Langmuir, vol. 18, no. 21, pp. 7821-7825, 2002.

[18] M. N. Khan, "A new semi-empirical kinetic method for the determination of ion exchange constants for the counterions of cationic micelles," Advances in Colloid and Interface Science, vol. 159, no. 2, pp. 160-179, 2010.

[19] M. N. Khan, Z. Arifin, E. Ismail, and S. F. M. Ali, "Effects of $[\mathrm{NaBr}]$ on the rates of intramolecular general base-catalyzed reactions of ionized phenyl salicylate ( $\mathrm{PS}^{-}$) with $n$-butylamine and piperidine in the presence of cationic micelies," The Journal of Organic Chemistry, vol. 65, no. 5, pp. 1331-1334, 2000.

[20] N. S. M. Yusof and M. N. Khan, "A quantitative correlation of counterion (X) affinity to ionic micelles and $\mathrm{X}$ and temperature-induced micellar growth (spherical-wormlike micelles-vesicles) for $\mathrm{X}=5$-methyl- and 5-methoxysalicylate ions," The Journal of Physical Chemistry B, vol. 116, no. 7, pp. 2065-2074, 2012.

[21] A. A. Ali and R. Makhloufi, "Effect of organic salts on micellar growth and structure studied by rheology," Colloid and Polymer Science, vol. 277, no. 2-3, pp. 270-275, 1999.

[22] T. Shikata, H. Hirata, and T. Kotaka, "Micelle formation of detergent molecules in aqueous media. 2. Role of free salicylate ions on viscoelastic properties of aqueous cetyltrimethylammonium bromide-sodium salicylate solutions," Langmuir, vol. 4, no. 2, pp. 354-359, 1988.

[23] Z. Lin, J. J. Cai, L. E. Scriven, and H. T. Davis, "Sphericalto-wormlike micelle transition in CTAB solutions," Journal of Physical Chemistry, vol. 98, no. 23, pp. 5984-5993, 1994. 

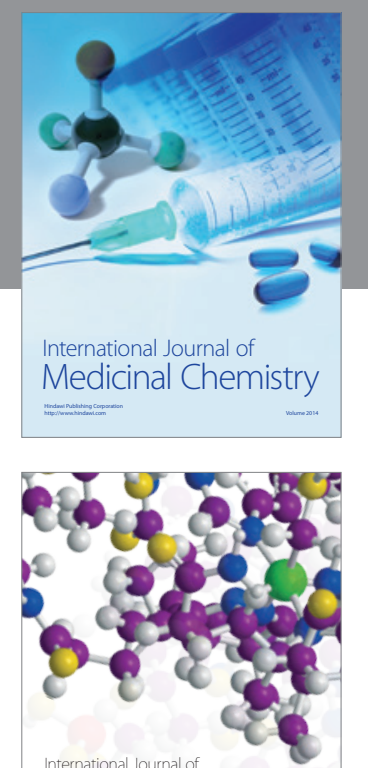

\section{Carbohydrate} Chemistry

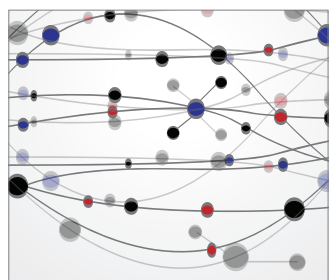

The Scientific World Journal
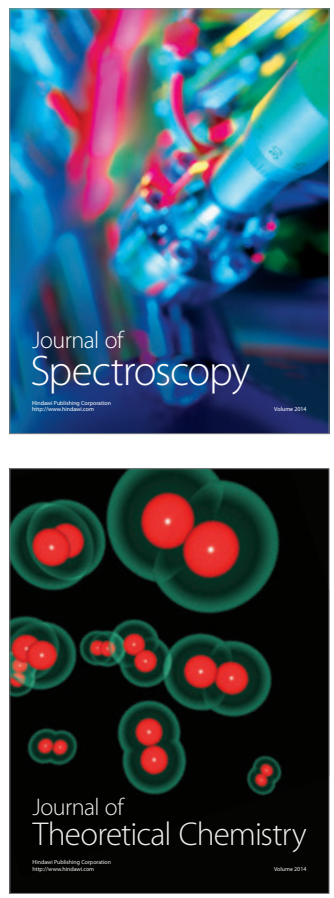
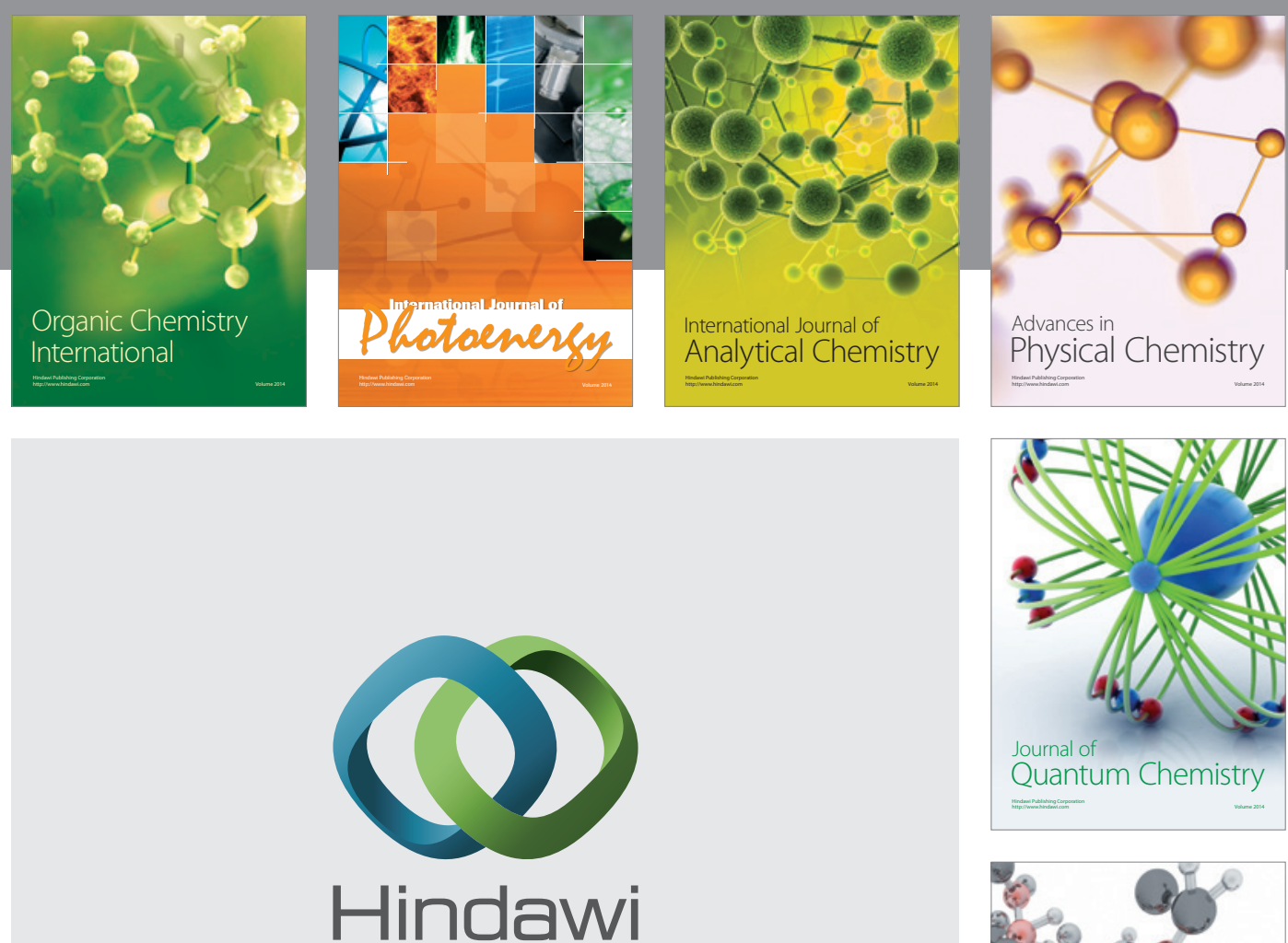

Submit your manuscripts at

http://www.hindawi.com

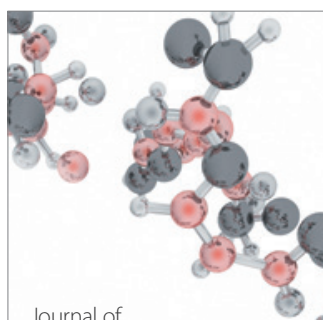

Analytical Methods

in Chemistry

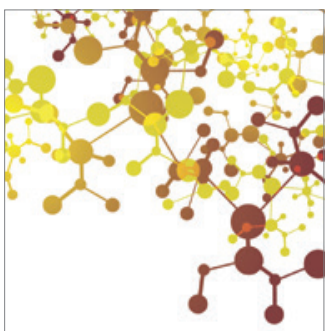

Journal of

Applied Chemistry

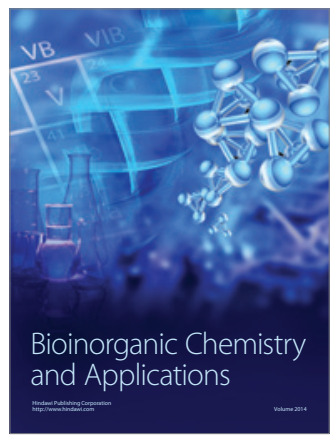

Inorganic Chemistry
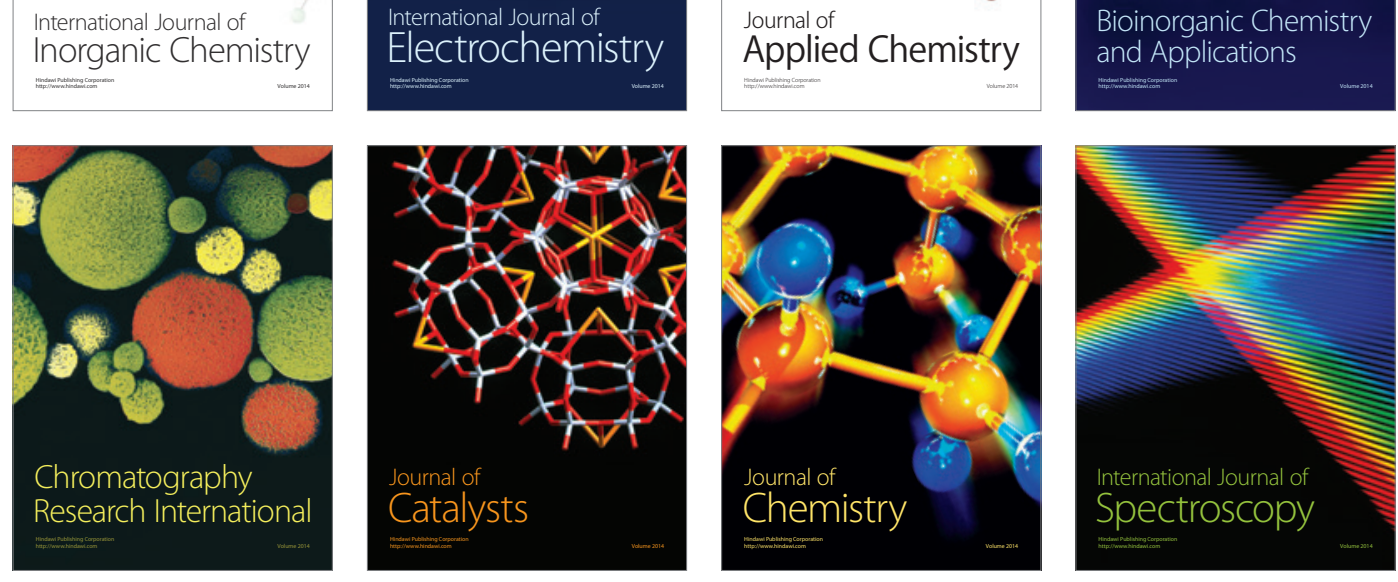